\title{
FUEROS, TIEMPO E INTEGRACIÓN CONSTITUCIONAL
}

JOSU DE MIGUEL BÁRCENA 


\section{SUMARIO}

1. INTRODUCCIÓN. 2. LA CUESTIÓN FORAL DURANTE EL SIGLO XIX: EL FUERO Y LOS FUEROS EN LA HISTORIA CONSTITUCIONAL ESPAÑOLA. 3. DERECHOS HISTÓRICOS Y LA CONSTITUCIÓN: ENTRE LA IDENTIDAD Y LA ARTICULACIÓN INSTITUCIONAL. 4. TIEMPO Y RÉGIMEN FORAL: UNA PROPUESTA DE CÁBALA CONSTITUCIONAL. 5. CONCLUSIONES. 


\title{
FUEROS, TIEMPO E INTEGRACIÓN CONSTITUCIONAL
}

\author{
JOSU DE MIGUEL BÁRCENA ${ }^{1}$ \\ Profesor visitante de derecho constitucional \\ Universidad de Cantabria
}

\section{INTRODUCCIÓN.}

En el presente trabajo, me propongo realizar una serie de reflexiones en torno a la evolución histórica del régimen foral en el País Vasco. Para ello, realizaré un recorrido donde trataré de analizar la relación entre los fueros y el constitucionalismo español en términos de tensión e integración, evidenciando que dicho régimen ha sido globalmente fecundo en el proceso de conformación de la comunidad política vasca y española desde el siglo XIX. No obstante, se advierte que, como en el pasado, el peligro en torno a la persistencia y funcionalidad del sistema foral, entendido en sentido general, reside en su inacabado proceso de actualización política, sobre todo teniendo en cuenta el canon elaborado por un nacionalismo que sigue buscando la forma de aislar al País Vasco y su autogobierno de la influencia del constitucionalismo español. Dicho canon, como trataremos de explicar, ha encontrado indudables posibilidades en el contexto del juego ideológico que ha dado y sigue dando el contenido de las Disposiciones Adicionales, Transitorias y Derogatoria de la Constitución de 1978.

\section{LA CUESTIÓN FORAL DURANTE EL SIGLO XIX: EL FUERO Y LOS FUEROS EN LA HISTORIA CONSTITUCIONAL ESPAÑOLA.}

En efecto, como es de todos conocido, la Disposición Adicional $1^{a}$ de la Constitución española «ampara y respeta los derechos históricos de los territorios forales». No puede dejar de llamarse la atención sobre la maniobra de incluir fragmentos

\footnotetext{
1 Profesor visitante de Derecho Constitucional. Facultad de Derecho. Av. de los Castros, s/n, 39005 Santander (Cantabria). Email: dospasoss@hotmail.com 
históricos en una norma que aspiraba a racionalizar el proceso político a partir de los valores y la metodología ilustrada y moderna. La queja inicial de García - Pelayo tenía su base, probablemente, en su conocimiento exhaustivo de una problemática conceptual que discurrió inicialmente en el marco del desmembramiento de los imperios centroeuropeos tras la I Guerra Mundial ${ }^{2}$. También en la importancia que para él tenían las categorías en la Teoría de la Constitución. Sin embargo, quizá debiéramos reconocer que la Constitución de 1978 no se corresponde propiamente con un modelo cartesiano de constitucionalismo que a veces presuponemos: el tratamiento del tiempo que hace por ejemplo la Disposición Adicional $1^{\text {a }} \mathrm{CE}$, revela un alejamiento de los «horizontes de expectativa» contemporáneos y la incorporación de «espacios de experiencia preexistentes» tal y como los ha venido a definir Koselleck ${ }^{3}$. Conviene concretar brevemente a qué espacios de experiencia preexistentes nos referimos, al margen de las consideraciones que puedan hacerse sobre la teoría y la praxis de un poder constituyente, el español, que en 1978 trató de deslizarse desde el decisionismo tradicional hacia un plano más evolutivo ${ }^{4}$.

En términos territoriales, la Constitución limita los espacios de experiencia preexistentes al régimen foral vasco y navarro y a los territorios que en el pasado (II República) hubieran plebiscitado proyectos de Estatuto, con el objeto de facilitar un mayor nivel competencial y permitir una vía más sencilla para elaborar la norma estatutaria (Disposición Transitoria 2a). Como se sabe, en la sentencia 31/2010, sobre el Estatuto de Cataluña, el Tribunal Constitucional atajó la pretensión del legislador orgánico - estatutario de atribuir a la Comunidad Autónoma un autogobierno sustentado en derechos históricos: tales derechos solo son predicables de los territorios forales reconocidos en la Disposición Adicional 1a (FJ 10). Dicho argumento se ha vuelto a repetir en la reciente STC 158/2019, donde se aborda la constitucionalidad de la Ley autonómica 8/2018 que trataba de actualizar los derechos históricos de la Comunidad Autónoma de Aragón.

Más allá de estas cuestiones cercanas, resulta necesario advertir que la «cuestión foral» española es probablemente consecuencia de la crisis hispánica que se origina con la invasión francesa y el proceso constituyente de Cádiz. En ese periodo entra en crisis no solo el dominio colonial de la Corona, sino también el mecanismo premoderno que habría permitido hasta ese momento insertarse a las provincias vascas y a Navarra en un Estado donde empezaba a vislumbrarse la tensión entre la lógica liberal y las instituciones del Antiguo Régimen. La pérdida progresiva de las colonias tras

${ }^{2}$ García - Pelayo, M. (1979). El tema de las nacionalidades. La teoría de la nación en Otto Bauer. Madrid: Fundación Pablo Iglesias.

3 Koselleck, R. (1993). Futuro pasado: para una semántica de los tiempos históricos. Barcelona: Paidós. Sobre la relación entre el tiempo y la historia también resultan de gran interés Blumenberg, H. (2007). Tiempo de la vida y tiempo del mundo. Valencia: Pre - Textos y algunos capítulos del libro de Benigno, F. (2013). Las palabras del tiempo. Un ideario para pensar históricamente: Madrid: Cátedra.

${ }^{4}$ Coincidimos en esta perspectiva con la tesis de García López, E. (2013). Apuntes para una relectura heterodoxa de la transición política en España. Estudios de Deusto, Vol. 61/1. 
la vuelta de Fernando VII y el levantamiento carlista tras la muerte de este último, puede verse como un proceso paralelo y diacrónico que al interior logra resolverse mediante la Ley de compromiso de octubre de 1839: la unidad constitucional de la monarquía en España supone, paradójicamente, el cumplimiento del sueño criollo que no había podido alcanzarse en Américas

Entre 1839 y 1876 se vive en las provincias vascas lo que podríamos denominar como la «edad de oro foral». Periodo parcialmente desconocido, es el momento en el que la falta de voluntad de los patricios vascos y la dejadez estatal permiten sustentar un mito político y jurídico que, en buena medida, aún sigue en pie. La invención de la nueva tradición, por decirlo en los términos de la historiografía marxista, es posible porque en Álava, Guipúzcoa y Vizcaya no se reconstruye el régimen foral de la misma forma que en Navarra: en dicha provincia, como bien se sabe, la Ley de Cortes de agosto de 1841 permite organizar su administración general, con importantes peculiaridades económicas, organizativas y fiscales.

En las por aquel entonces Vascongadas, sin embargo, la eliminación de las aduanas interiores, del sistema judicial propio y de la hidalguía como privilegio de acceso a la función pública realizada prontamente por Espartero, no evita que las nuevas diputaciones disfruten de un sistema fiscal casi completamente ajeno a la hacienda estatal y que los jóvenes, por ejemplo, no realizaran el servicio militar obligatorio gracias a la exención de quintas. En la práctica, la edad de oro foral aludida supuso una prolongación de los mecanismos de administración territorial ampliamente puestos en práctica por las monarquías autoritarias desde el siglo $\mathrm{XVI}^{6}$.

Durante ese tiempo se producen dos fenómenos de gran importancia. El primero tuvo que ver con la ampliación del poder efectivo de las diputaciones, que dotó al régimen foral de una estructura centralizada de la que había carecido durante el Antiguo Régimen. Los sucesivos gobiernos del Estado vinieron a aceptar, de forma implícita, el criterio amplio con el que Julián Egaña y otros definían la «estructura foral», en cuya órbita se incluía definitivamente el control de los ayuntamientos, locus donde tradicionalmente se habían desplegado las facultades incluidas en el Fuero. Durante el siglo XIX, gracias a la labor proselitista realizada por las instituciones propias, se consolida la ideología de los fueros frente al Fuero. Si éste último contenía distintos tipos de normas de las que se hacía un uso a beneficio de inventario por parte de la cultura política provincial, los fueros eran una especie de jurisprudencia o common law que los órganos de gobierno provinciales habían logrado controlar en exclusiva, con el objetivo de parapetarse frente al avance material de un constitucionalismo liberal. Desde el punto de vista de lo económico y las relaciones de poder, el monopolio intelectual y político sobre el fuerismo naciente fue muy beneficioso para las élites locales.

5 Como ha sugerido Portillo Valdés, J.M. (2006). Crisis atlántica. Autonomía e independencia en la crisis de la monarquía hispana. Madrid: Marcial Pons.

${ }^{6}$ Fernández Albadalejo, P. (1982). Guipúzcoa 1839 - 1868: la recomposición de una sociedad, en Jiménez de Aberasturi, J.C. (Coord.), Estudios de historia contemporánea del País Vasco. San Sebastián: Luis Haranburu.

(C) UNED. Revista de Derecho Politico

N. ${ }^{\circ} 108$, mayo-agosto 2020, págs. 285-298 
Fue precisamente durante la etapa isabelina cuando se construyó una comunidad imaginada compuesta por el tríptico «fueros, religión y lengua». La identidad vasca — si tal expresión pudiera ser trasladada a esa época — se articuló mediante un pacto entre liberales y tradicionalistas que expresaba la tensión entre el campo y la ciudad: al igual que en Navarra, la preferencia de la comunidad frente al individuo, la proliferación de un elitismo cultural tradicional y la consolidación de las estructuras aristocráticas donde jugaba un papel esencial la Iglesia católica, permitieron construir una barrera frente a los vientos de una modernización que traía secularización, contractualismo y positivismo científico ${ }^{7}$.

Pese a lo que pudiera parecer, esta construcción identitaria no fue un proyecto necesariamente divisivo, sino que gracias a la connivencia con el moderantismo se terminó presentando a lo vasco y lo foral como paradigmas de una nación española costumbrista que trataba de afirmarse frente al modelo centralista y ciudadano que pudiera provenir de Francia y otros espacios constitucionales europeos. La españolidad se interpretaba en muchos casos como la expresión fragmentada de dos cuerpos asociativos: súbdito — corona y provincia - nación. Este equilibrio, como el lector ya conoce, se rompe a causa de las tres guerra carlistas o civiles que tienen lugar a lo largo del siglo XIX como consecuencia del conflicto sucesorio surgido en 1833, tras la muerte de Fernando VII ${ }^{8}$.

En tal sentido, Molina Aparicio, ha señalado que la tercera guerra carlista, surgida como reacción al Sexenio revolucionario, constituye un momento de ruptura con respecto a la dinámica anteriormente señalada9 ${ }^{9}$ Siguiendo a Galdós, las provincias vascas se habrían convertido en la «tierra del martirio español», produciéndose una reacción de la opinión pública y la clase política española contra un régimen de autogobierno, el foral, cuyas amplias competencias financieras y militares habrían facilitado el largo conflicto armado.

No es baladí, tampoco, cómo se aprovecha dicho conflicto para delimitar la nación liberal en torno a una cierta idea entre el amigo y el enemigo, aunque lo importante sea precisar aquí que el ambiente poco conciliador convence a Cánovas de que los fueros no son compatibles con el sistema político que se intenta introducir con la Constitución de 1876. Desaparecida —o transformada, como veremos a continuación— la foralidad vasca, queda un vacío ideológico muy grande que es aprovechado por una nueva ideo-

\footnotetext{
7 Ver a este respecto Mina Apat, M.C. (1981). Fueros y revolución liberal en Navarra. Madrid: Alianza. Sobre la identidad vasca en el ochocientos, ver Rubio Pobes, C. (2003). La identidad vasca en el siglo XIX. Discurso y agentes sociales. Madrid: Biblioteca Nueva.

${ }^{8}$ Para todas estas cuestiones, de forma genérica, Artola, M. (1990). La burguesía revolucionaria (1808-1874). Madrid: Alianza y más recientemente de Martorell, M. y Juliá, S. (2014). Manual de historia política y social de España (1808-2011). Madrid: RBA.

9 Molina Aparicio, F. (2005). La tierra del martirio español. El País Vasco y España en el siglo del nacionalismo. Madrid: Centro de Estudios Políticos y Constitucionales.
} 
logía que complementando el romanticismo y el integrismo religioso, se termina consolidando desde finales del siglo XIX hasta nuestros días: el nacionalismo ${ }^{10}$.

La Ley derogatoria de fueros de Vizcaya, Guipúzcoa y Álava de 1876, constituye el final del régimen foral de las provincias vascas. A diferencia de la Ley de octubre de 1839 y, sobre todo, de la modificación realizada en Navarra a través de la Ley de 1841, la Ley de julio de 1876 no garantiza ninguna especificidad institucional, limitándose a dejar las puertas abiertas a una redefinición que dependía de la voluntad del gobierno. Así ocurre finalmente con la Real Orden de 12 de diciembre de 1877, que recuperaba ciertas competencias de control municipal para las nuevas diputaciones provinciales y, sobre todo, con los Reales Decretos de noviembre de 1877 y febrero de 1878, donde se consagra un concierto económico que otorga también a las diputaciones provinciales un procedimiento para establecer sus propios impuestos y el correspondiente señalamiento que ha de pagarse al Estado.

Resulta paradójico que un sistema que surge precisamente para sustituir al régimen foral, sea con el paso del tiempo considerado como un derecho histórico que tiene que estar constitucionalmente garantizado. Desde este punto de vista, cabría una doble interpretación, partiendo de las dos primeras acepciones que la Real Academia otorga a la palabra concierto: «buen orden y disposición de las cosas» o «ajuste o convenio entre dos o más personas o entidades sobre algo» ${ }^{11}$.

\section{DERECHOS HISTÓRICOS Y CONSTITUCIÓN: ENTRE LA IDENTIDAD Y LA ARTICULACIÓN INSTITUCIONAL.}

Desde 1876 hasta prácticamente el periodo constituyente que se va concretando un siglo después, el concierto económico fue la base del autogobierno vasco. Su renovación general se produce en 1887, 1894, 1906 y 1926. Por supuesto, hasta prácticamente la Guerra Civil, se vive un proceso de apropiación política por parte del nacionalismo, que hace suyo el mito sabiniano que convierte la situación previa a 1839 en la época en la que las provincias vascas habrían disfrutado de auténtica soberanía proyectada en el pacto voluntario con la Corona. A través de un remedo de la traslatio imperii medieval, se afirma que incumplidas las condiciones del contrato foral, los vascos podrían recuperar su antigua independencia.

Durante este tiempo, aparece el concepto de derechos históricos (1917) y se reivindican su institucionalización (Estatuto de Estella de 1931) aunque, sorprendentemente, en el Estatuto de 1936 no aparecen referencias al régimen foral ${ }^{12}$. Como se

\footnotetext{
${ }^{10}$ Corcuera Atienza, J. (1980). Orígenes, ideología y organización del nacionalismo vasco (1876 - 1904). Madrid: Siglo XXI.

${ }^{11}$ Como han apuntado Castells, L. y Cajal, A. (2005). La negociación imposible (Cánovas y el fuerismo vasco en 1876). Hispania, LXV/2, núm. 220, 2005.

12 Corcuera Atienza, J. (2015). Los derechos históricos. ¿Un instrumento para la desarticulación de la nación española?, en Molina, F. y Pérez, J.A (Eds.). El peso de la identidad. Mitos y ritos de la historia
} 
sabe, el Decreto - Ley de 23 de junio de 1937, una nueva planta parcial impuesta por el incipiente Estado franquista, liquida para Vizcaya y Guipúzcoa, «provincias traidoras», el concierto económico, manteniéndose sin embargo para Álava. Navarra seguirá disfrutando durante el franquismo del sistema foral creado a partir de lo que algunos han llamado la «Ley paccionada» de 1841.

El proceso constituyente iniciado prácticamente en 1976, tiene especial relevancia desde el punto de vista de lo que puede llamarse integración constitucional. Solozábal ha llamado la atención sobre la dualidad que cabe atribuir a la naturaleza de la distribución territorial española: la articulación tendría que ver con el momento institucional, es decir, con la forma en la que los distintos niveles racionalizan el ejercicio del poder, mientras que la integración sería un proceso relacionado con la identidad y la fenomenología del poder ${ }^{13}$. A partir de esta dialéctica, pueden detectarse numerosas cláusulas de integración territorial en la Constitución de 1978, como la lengua, los símbolos o los derechos históricos ${ }^{14}$.

A los derechos históricos cabe atribuirles una funcionalidad en el sistema constitucional muy similar a la que ha jugado la Corona: su accidentalidad no ha impedido que hayan servido para lograr una mejor integración de la comunidad política dual en términos de beneficio económico y simbolismo político. La accidentalidad hay que contemplarla desde la perspectiva de un cuestionable originalismo y de un zeitgeist dominado por el principio democrático. Y es que lo que sigue desafiando a la Corona $\mathrm{y}$ al propio régimen foral no es solo el republicanismo o el centralismo, sino el despliegue de la igualdad como criterio rector de las sociedades. La incorporación de los derechos históricos a los Estatutos de nueva generación de la década de 2000 (Valencia, Cataluña y Aragón), es la consecuencia de la paradójica democratización del derecho a la diferencia, no solo de la conocida emulación institucional que caracteriza al Estado autonómico desde sus comienzos ${ }^{15}$.

Llegados a este punto, merece la pena volver sobre una cuestión advertida con anterioridad: el ejemplar uso del tiempo que hace la Constitución de 1978 para intentar la integración territorial del nacionalismo vasco (y el foralismo navarro). Como bien se sabe, el tiempo afecta a las Constituciones teniendo en cuenta su capacidad para adaptarse a la realidad, este es el motivo por el cual se prevén mecanismos de reforma de las Normas Fundamentales ${ }^{16}$. Sin embargo, como es el caso de la

\footnotetext{
vasca. Madrid: Marcial Pons.

${ }^{13}$ Solozábal, J.J. (2017). España: nación de naciones, El Cronista del Estado social y democrático de Derecho, núm. 68.

${ }_{14}$ Hemos explorado estas cláusulas en Miguel Bárcena, J. de (2018). Las cláusulas constitucionales de integración territorial. Cuadernos Manuel Giménez Abad, nº 20, pp. 367 - 400.

15 Rey Martínez, F. (2006). El concepto de los «derechos históricos» en la reforma de los estatutos de autonomía, Cuadernos de Alzate: revista vasca de la cultura y de las ideas, núm. 24.

16 Tajadura, J. (2018). La reforma constitucional: procedimientos y límites. Madrid: Marcial Pons.
} 
retroactividad, las Constituciones también pueden hacer uso del tiempo para construir puentes entre el pasado y el presente ${ }^{17}$.

El aparataje previsto por nuestra Constitución en las disposiciones adicionales, transitorias y derogatorias tiene como objetivo incorporar y consolidar un sistema de autogobierno al que el Tribunal Constitucional y parte de la doctrina han dado carácter de garantía institucional. La historia penetra en nuestro constitucionalismo como factor de estabilización fusionándose con el racionalismo positivista: la Norma, producto de un poder constituyente soberano, es la ordenación de una realidad preexistente con la que se establece un diálogo fecundo de amplias implicaciones, pues ni aquella puede negar los componentes primordiales del sustrato social que la soporta, ni la sociedad se consolida sin las reglas que la estructuran y posibilitan su reproducción ${ }^{18}$.

La recomposición del sistema foral comenzó prontamente con los Decretos - Leyes que en marzo y junio de 1977 recuperaron un autogobierno aún precario para las provincias vascas. El movimiento inicial de las autoridades franquistas y los incipientes partidos estatales, que también buscaba reducir el impacto de la violencia terrorista, fue atendido inmediatamente por una nacionalismo vasco que, como recordaba Herrero de Miñón, obligó a sus parlamentarios constituyentes a volver sobre Fidel de Sagarmínaga tras la amnesia foral producida durante el franquismo.

Aquellas lecturas y reinterpretaciones dieron como resultado la recuperación de un milenarismo patriótico que reclamaba, eludiendo la pretensión máxima de la independencia, la vuelta a una situación de soberanía originaria negada por intereses ajenos al País ${ }^{19}$. Como se sabe, tras intensos debates en torno a la soberanía, el Rey y otras cuestiones relacionadas con la descentralización, la Disposición Adicional $1^{\text {a }}$ terminó reconociendo y amparando unos derechos históricos de los territorios forales cuya actualización debía realizarse en el marco constitucional. La aparición de esta cautela, similar a la establecida en la Ley de octubre de 1839, hizo que el nacionalismo vasco pidiera la abstención en el referéndum constitucional de 6 de diciembre de 1978: la historiografía ha demostrado el carácter estratégico de aquella posición, que buscaba otorgar ventajas políticas en el próximo entramado institucional que se iba a crear a partir del Estatuto ${ }^{20}$.

17 Azpitarte, M. (2008). Cambiar el pasado. Madrid: Tecnos. Una perspectiva más técnica y no por ello menos fecunda, en el trabajo de Diez Picazo, L.M. (1990). La derogación de las leyes. Madrid: Civitas.

${ }_{18}$ Corcuera Atienza, J. y García Herrera, M.Á. (2002). La constitucionalización de los Derechos Histórico. Madrid: Centro de Estudios Políticos y Constitucionales.

19 Aranzadi, J. (2000). Milenarismo vasco. Edad de oro, etnia y nativismo. Madrid: Taurus.

${ }^{20}$ Desde un punto de vista constitucional, ver Corcuera Atienza, J. (1991). Política y Derecho. La construcción de la autonomía vasca. Madrid: Centro de Estudios Constitucionales. 


\section{TIEMPO Y RÉGIMEN FORAL: UNA PROPUESTA DE CÁBALA CONSTITUCIONAL.}

Con la Constitución de 1978 se concreta entonces lo que se conoce como fuerismo constitucional. Volver sobre la idea de que los derechos históricos tienen que confluir en y respetar el ordenamiento constitucional no es nada nuevo. Interesa, por el contrario, explorar otras cuestiones relacionadas con un diálogo que ha servido para estabilizar el Estado, la política y la sociedad, función constitucional esencial ya apreciada por Pocock en el paso de la edad media a la moderna en sus conocidos trabajos sobre el tema y que no es en absoluto ajena a la Teoría de la Constitución como límite que se fue desarrollando más tardíamente ${ }^{21}$. Naturalmente, la estabilización política tiene que ver con el problema territorial que España arrastra y conlleva, por decirlo en términos orteguianos, desde que comenzó la modernización de sus estructuras jurídicas en el siglo xix. Proponemos, de este modo, una especie de «cábala constitucional» partiendo del contenido de las Disposiciones Adicional 1a , Transitorias y Derogatoria de la Constitución de 1978.

Como se sabe, la vaguedad del Estatuto vasco en lo relativo a lo foral ha ido desapareciendo gracias a la actuación del legislador estatal y autonómico. Dicha actuación nos remite a un largo (e inacabado) proceso donde la definición de la foralidad es el resultado de opciones de las diversas mayorías, y no el desarrollo de esencias históricas. Resultan innumerables las leyes del Estado que a través de disposiciones adicionales han establecido reservas que exceptúan o garantizan las peculiaridades vascas al margen de lo regulado con carácter general por la norma. Ello demuestra la importancia de la negociación entre partes y la capacidad de los nacionalistas para presentar la construcción de la autonomía vasca como la invocación de unos derechos históricos que justifican las demandas de la Comunidad. Las pretensiones se han orientado, particularmente, a fortalecer la posición de los Territorios Históricos en materia fiscal y financiera.

Tampoco puede obviarse que una de las grandes novedades de la actualización de los derechos históricos en términos estatutarios ha sido el proceso de centralización en beneficio de la comunidad política vasca en su conjunto. Recordemos que algo parecido había ocurrido con las diputaciones y los ayuntamientos en el siglo XIX. En lo tocante a la Legezarra el nacionalismo, con el consenso de los partidos no nacionalistas, había visto en 1979 realizado su programa y algo más. Ese «algo más» se concretó en un diseño de nueva planta, ya aludida, que también implicó una profunda

21 Pocock, J. G.A. (2011). La Ancient Constitution y el derecho feudal. Madrid: Tecnos. Aragón apuntó, en su trabajo sobre supremacía y supralegalidad, que desde la antigüedad la idea de Constitución reivindica una estabilidad a la que se llega a través de la noción de límite: «Si la comunidad política ha de persistir es imprescindible que el poder tenga, al menos, la limitación mínima de no alcanzar a destruirla; si la comunidad política ha de persistir en una determinada forma política, esta será también un límite infranqueable para el poder», en Aragón, M. (2013). Estudios de derecho constitucional. Madrid: Centro de Estudios Políticos y Constitucionales, p. 174, cursivas nuestras. 
alteración de la foralidad tal y como tradicionalmente se entendía. Esta alteración viene dictada por la presencia de un nuevo sujeto, el pueblo vasco, que resulta una noción extraña al régimen foral. En términos prácticos, esta profunda transformación permitió, por ejemplo, incorporar al Estatuto competencias donde el Estado tenía reservada una actuación a través de ley orgánica, como fue el caso de la educación y policía, que encontraron sustento no en los arts. 148 y 149 CE, sino en la Disposición Adicional $1{ }^{a} \mathrm{CE}$.

Pero más allá de estas cuestiones, ya conocidas, el nacionalismo vasco logró incorporar a la Constitución territorial de 1978 cuestiones de alto valor simbólico, pese a la tradicional queja que imputa al poder constituyente un cierto autismo con respecto a sus demandas identitarias. Su idea de autogobierno preexistente a la Constitución queda reflejada en la Disposición Transitoria $2^{a}$, donde se ancla un dato esencial del aspecto más controvertido del Estado español en un precedente - la II Repúblicade indudable legitimidad para unos, pero no tanto para otros. Los esfuerzos del Tribunal Constitucional por negar la fuerza normativa de los fragmentos territoriales previos, evidencian el problema de tener que encajar en la nueva gramática constitucional una devolución de poderes al País Vasco, Cataluña y Galicia que logra incardinar, en un movimiento inaudito desde la perspectiva del tiempo jurídico, el Texto Constitucional de 1978 con el de 1931. Así las cosas, la línea divisoria que traza la Disposición Transitoria $2^{a}$ sigue sirviendo de importante fundamento a los partidarios de interpretar como voluntad constituyente la diferenciación entre nacionalidades y regiones que no quiere hacer el art. 2 CE y que vendría a legitimar regímenes de autonomía asimétricos en lo relativo a las competencias, la financiación y el sistema institucional ${ }^{22}$.

La Disposición Derogatoria $2^{\mathrm{a}}$ CE también contiene una particular concepción de la relación histórica entre España y el País Vasco: abole las Leyes de 1839 y 1876 , pero no dice nada del Decreto — Ley de 23 de junio de 1937, que acaba con el concierto para Vizcaya y Guipúzcoa en plena Guerra Civil. Esta derogación, como se reflejó en el debate constitucional, tuvo una dimensión no tanto jurídica como emocional para Álava, Guipúzcoa y Vizcaya: al fin y al cabo, como señala el Código Civil, por la simple derogación de una norma no recobran vigencia las que ésta hubiere derogado. El rechazo expreso a la legislación foral del Estado del siglo XIX — las únicas leyes de fueros que existían- era y sigue siendo una parte sustancial del posicionamiento de independencia constitucional del nacionalismo vasco con respecto a España: independencia de la Constitución y del constitucionalismo español, de cualquiera, aunque pueda permanecer una vinculación al Estado siempre a la carta, como

22 El criterio diferenciador histórico del plebiscito estatutario que tuvo lugar no aparece especialmente determinante si se recuerda que no hubo más proyectos estatutarios plebiscitados porque las dramáticas circunstancias consabidas en la II República abortaron otros proyectos autonomistas en curso. Por otro lado, como se sabe, la propia Constitución prevé en sus arts. 148.2 y 151.1 los mecanismos necesarios para que todas las Comunidades Autónomas tuvieran el mismo nivel competencial e institucional desde el mismo inicio del proceso autonómico o pasados cinco años.

(C) UNED. Revista de Derecho Político

295

N. ${ }^{\circ} 108$, mayo-agosto 2020, págs. 285-298 
demuestra el transcurrir de expresiones institucionales bien cercanas y que en seguida aludiremos ${ }^{23}$.

Esta exégesis permite poner en valor la potencia simbólica de la Constitución para atender las demandas territoriales del País Vasco y Navarra. Capacidad que, como hemos visto, se ha sustentado en un peculiar uso del tiempo que ha sido poco ponderado. Ahora bien, con todo este esfuerzo se colaba en la Constitución el polizón confederal, porque el material incorporado a las Disposiciones aludidas proporciona una baza interpretativa de gran alcance cuando se trata de abordar la evolución y la reforma de la Constitución territorial española. La actualización permanente del régimen foral, que ha mostrado un gran dinamismo sobre todo en el contexto del legislador de las Cortes (véase la LO 1/2010 sobre reforma de la Ley Orgánica del Tribunal Constitucional), ha permitido expresar nuevas demandas que no hacen sino confirmar la idea de que el nacionalismo vasco quiere afirmar su ser dentro del Estado pero desconectando progresivamente de la propia Constitución. Y este modo de operar no debe causarnos extrañeza, porque el historicismo vinculado al nacimiento de las naciones románticas está en el origen del subjetivismo cognitivo y quizá del relativismo temporal: a cada nación le corresponde una verdad constitucional ${ }^{24}$.

El plan Ibarretxe a comienzos del siglo XxI, y últimamente las Bases de la Ponencia para la actualización del autogobierno de Euskadi, culminan la recreación del sujeto político (la nación foral) y expresan una nueva articulación de la relación del País Vasco con España que cabalga a lomos del derecho a decidir y una renovada concepción del viejo «pase foral» que rechaza aquellas instancias jurisdiccionales que pretendan resolver de manera definitiva los conflictos planteados entre niveles de $\operatorname{poder}^{25}$. Lo importante aquí no es una posible incoherencia estructural (foralismo y derecho de secesión), sino la determinación de un proyecto político nacional que parte de unas reivindicaciones previamente cinceladas en normas constitucionales cuyo significado y posición geográfica en la Norma Fundamental, avalan la importancia del uso del tiempo a la hora de estabilizar históricamente las comunidades políticas. Naturalmente, el rendimiento de ese uso también puede mostrar el fracaso del proyecto global.

23 Portillo Valdés, J.M. (2018). Entre tiros y autonomía. La constitución de la autonomía vasca (1976 - 1979). Barcelona: Galaxia Gutenberg.

${ }^{24}$ Lamo Espinosa, E. (2019). A propósito de la posverdad. Revista de libros, 2019, última consulta 27/07/2019, https://www.revistadelibros.com/articulos/a-proposito-de-la-posverdad

25 Tomo esta idea de López Basaguren, A. (2019). El País Vasco, el modelo de autonomía territorial y la pretensión constitucional del nacionalismo, Fundamentos. Cuadernos monográficos de teoría del Estado, derecho público e historia constitucional, núm. 10, 2019, que alude a la desconfianza permanente del nacionalismo vasco hacia la justicia constitucional como mecanismo para resolver los conflictos planteados en el marco de la descentralización política. 


\section{CONCLUSIONES.}

En este breve trabajo hemos pretendido hacer un breve recorrido sobre la relación entre los fueros y el constitucionalismo español desde el siglo XIX hasta nuestros días. Dicha relación puede caracterizarse como una larga dialéctica entre la cooperación y el conflicto institucional. Al día de hoy existe en el País Vasco una interpretación dominante que considera el foralismo como una doctrina autorreferencial que puede terminar expresando potencial constituyente y estatalidad. Esta idea nos parece discutible porque el sistema organizativo sobre el que aquellos están asentados solo encuentra sentido en una contraparte jurídica que lo garantice. Sin embargo, predomina el conflicto institucional sobre la cooperación y la lealtad constitucional: quizá porque el poder constituyente, en su intento de dar satisfacción a las demandas nacionalistas, estableció normas constitucionales que formulan mitos políticos y concepciones ideológicas que sirven tanto para integrar identidades como para poner en cuestión la consolidación federal del Estado autonómico. El tiempo de descuento de la Constitución, compuesto por las arcanas Disposiciones Adicionales, Transitorias y Derogatoria, muestra que la crisis territorial del Estado también debe explicarse a partir de sus propias paradojas.

Conviene tener en cuenta esta afirmación cuando nos preguntamos si la solución constitucional aquí analizada es trasladable al contencioso catalán que se agrava a partir de 2012. Muchas han sido las propuestas que buscan encajar las aspiraciones del nacionalismo catalán en una «disposición adicional a la vasca» o a través de otras formas de asimetría constitucional. El primer problema que aquí habría que abordar es si tales cláusulas son atendibles por el poder de reforma o solo son posibles en el ambiente político excepcional que preside los procesos constituyentes ${ }^{26}$. El segundo, y no menos importante, tiene que ver precisamente con alguna de las cuestiones aquí desarrolladas: la historia y el tiempo son elementos que permiten la continua reelaboración de las raíces constitucionales del ordenamiento. Sin embargo, su inserción artificial en la actual Constitución, obligaría a buscar un equilibrio muy complejo entre legitimidad, credibilidad e igualitarismo democrático: y es que 40 años de federalismo en España tampoco pasan en balde.

${ }^{26}$ Castellà Andreu, J.M. (2018). Estado autonómico: pluralismo e integración constitucional. Madrid: Marcial Pons.

(C) UNED. Revista de Derecho Politico

N. ${ }^{\circ} 108$, mayo-agosto 2020, págs. 285-298 
Title.

The fueros, the time and the constitutional integration.

\title{
Summary:
}

1. Introduction. 2. The Foral question during the 19th century: The fuero and the fueros in Spanish Constitutional History. 3. Historical Rights and the Constitution: between identity and institutional articulation. Time and the Foral Regime: A proposal for a constitutional speculation. 5. Conclusions.

\section{Resumen.}

El presente trabajo pretende realizar un acercamiento a la cuestión foral, desde el punto de vista de la integración constitucional. Para ello, realiza en primer lugar una aproximación histórica al régimen foral hasta la aprobación de la Constitución española en 1978. En segundo lugar, propone una nueva interpretación del régimen foral previsto en la Norma Fundamental, teniendo en cuenta el concepto de tiempo constitucional y su importancia en la tarea de dar estabilidad al Estado, la sociedad y la política. En tercer y último lugar, advierte los problemas actuales en torno la reforma de la Constitución territorial española y la pretensión de sustituir la historia institucional por el mito nacionalista.

\begin{abstract}
Abastract.
The present paper tries to make an analysis of the foral Question, from the point of view of constitutional integration. To do this, firstly, we make a historical approach to the foral regime untli the approval of the Spanish Constitution in 1978. Second, it proposes a new interpretation of the foral system in the Fundamental Norm, taking into account the concept of constitutional time and its importance in the task of giving stabilbity to the State, society and politics. Third and lastly, we warns of the current problems about the reform of the Spanish territorial Constitution and the intention of replacing institutional history by the nationalist myth.
\end{abstract}

\section{Palabras clave.}

Fueros, derechos históricos, tiempo, Constitución española, identidad.

Key words.

Fueros, historical rights, time, Spanish Constitution, identity. 